\title{
Производство печатных плат из многослойной керамики
}

\author{
Д. Яковлев ${ }^{1}$
}

УДК 621.315 | ВАК 05.27.06

\begin{abstract}
Керамические печатные платы из многослойной керамики применяются в составе гибридных электронных схем, в области силовой электроники, оптоэлектроники и СВЧ-техники, также они используются для электрической изоляции конструкций, узлов и элементов различных электронных устройств.
\end{abstract}

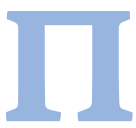

ечатная плата составляет основу любого электронного изделия, входя в состав компьютеров, сотовых телефонов и военной техники. Появившись более 100 лет назад, это маленькое устройство ознаменовало значительный скачок в развитии радиоэлектронной аппаратуры. Однако, вследствие постоянного ужесточения требований к печатным платам в связи с миниатюризацией изделий, разработкой высокоинтегрированных сборок и на фоне постоянно растущего количества технических требований к печатным платам, возникла необходимость внедрения в производство нового материала. Более того, получение максимальной производительности при минимальном занимаемом объеме неизбежно приводит к увеличению степени нагрева электронных компонентов и, как следствие, к значительно большему тепловыделению

Керамика обеспечивает эффективный теплоотвод от электронных компонентов с помощью материала основы. При монтаже основание платы может крепиться к радиатору. Пример такой платы показан на рис. 1.

В настоящее время в силовой электронике и микроэлектронике широко распространены керамические платы и подложки с использованием в качестве основы производственных процессов тонких или толстых пленок. Компанией "ТЕСТПРИБОР» освоены технологиИ изготовления однослойных и многослойных плат и подложек из вакуумплотной керамики на основе оксида алюминия $\left(\mathrm{Al}_{2} \mathrm{O}_{3}\right)$ и нитрида алюминия (AIN) как по толстопленочной технологии, так и по тонкопленочной.

Изделия из таких материалов характеризуются:

- высокой теплопроводностью;

- высокой степенью герметичности

- низким коэффициентом теплового расширения;

- низкими диэлектрическими потерями;

- высокой механической прочностью;

- высоким качеством обработки поверхности.

Первый шаг при проектировании печатных плат из керамики - это грамотный выбор материала подложки,

АО «ТЕСТПРИБОР», начальник производства, www.test-expert.ru который осуществляется исходя из технических требований заказчика. Производство АО «ТЕСТПРИБОР» изготавливает и поставляет различного рода спеченные керамические пластины, выполненные из:

- оксида алюминия $\mathrm{Al}_{2} \mathrm{O}_{3}$ с содержанием его в количестве 92,96 и 9९\%;

- нитрида алюминия AIN, в том числе полированного.

Характеристики подложек представлены в табл. 1. Толщина пластин варьируется от 0,127 до 2 мм, возможно изготовление подложек нестандартной толщины по документации заказчика.

В условиях прОИзводства АО "ТЕСТПРИБОР" освоена технология изготовления не только односторонних и двухсторонних плат на основе спеченной керамики, но и многослойных плат на основе сырой керамики.

Диаграмма процесса производства многослойных металлокерамических плат, а также примеры изделий,

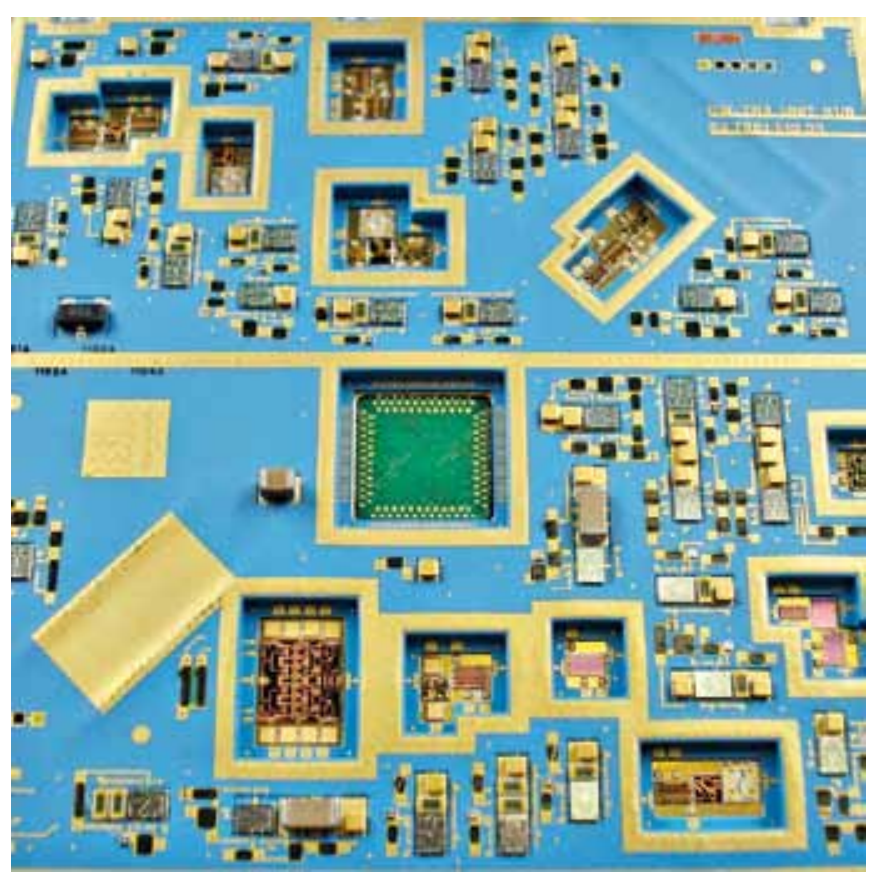

Рис. 1. Керамическая печатная плата 
Таблица 1. Типы и спецификации подложек

\begin{tabular}{|c|c|c|c|c|c|c|}
\hline $\begin{array}{l}\text { Материал } \\
\text { подложки }\end{array}$ & $\begin{array}{c}\text { Чистота, } \\
\%\end{array}$ & $\begin{array}{c}\text { Шероховатость } \\
\text { поверхности (А), } \\
\text { мкм }\end{array}$ & $\begin{array}{c}\text { Шероховатость } \\
\text { поверхности (В), } \\
\text { мкм }\end{array}$ & $\begin{array}{l}\text { Теплопро- } \\
\text { водность, } \\
\text { Вт / } \mathrm{M} \cdot \mathrm{K}\end{array}$ & $\begin{array}{c}\text { Диэлектриче- } \\
\text { ская постоянная, } \\
\text { на } 1 \text { МГц }\end{array}$ & $\begin{array}{c}\text { Тангенс угла } \\
\text { диэлектрических } \\
\text { потерь, на } 1 \text { МГц }\end{array}$ \\
\hline $\begin{array}{l}\text { Оксид алюми- } \\
\text { ния }\left(\mathrm{Al}_{2} \mathrm{O}_{3}\right)\end{array}$ & 99,6 & 3 & 3 & 26,9 & $9,9 \pm 0,1$ & 0,0001 \\
\hline $\begin{array}{l}\text { Полированный } \\
\text { оксид алюми- } \\
\text { ния }\left(\mathrm{Al}_{2} \mathrm{O}_{3}\right)\end{array}$ & 99,6 & 1 & $1 / 12$ & 26,9 & $9,9 \pm 0,1$ & 0,0001 \\
\hline $\begin{array}{l}\text { Нитрид алю- } \\
\text { миния (AlN) }\end{array}$ & 98 & 3 & 3 & 170 & 8,6 & 0,001 \\
\hline
\end{tabular}

изготовленных на основе технологии НТСС, представлены на рис. 2.

Многослойные печатные платы производства АО «ТЕСТПРИБОр» высококачественные, так как особое внимание уделяется контролю и выбору сырья, используемого при производстве керамики, а также многостадийному контролю производства на каждом этапе технологического процесса.

Обработка поверхности как спеченной, так и сырой керамики производится по Т3 заказчика. После обжига керамика может подвергаться полировке и шлифовке до требуемых значений плоскостности, параллельности и шероховатости.

Для формирования отверстий (сквозных, переходных, торцевых, межслойных), посадочных площадок и гнезд, колодцев и других элементов при производстве керамических плат применяются следующие виды механической обработки керамики:

- пробивка отверстий - используется исключительно в сырой керамике при небольших толщинах, позволяет получить почти идеальный край отверстия при высокой скорости обработки (до 500 отверстий в секунду), но имеет ограничения по геометрии и размерам производимых отверстий;

- лазерная обработка - проводится как по сырой, так и по спеченной керамике. Не имеет ограничений по геометрии и размерам формируемых элементов, но при обработке керамики толщиной от 0,2 мм выявляется небольшая конусность края получаемых элементов, что необходимо учитывать при разработке Т3, а при толщинах более 1 мм требуется применение технологически сложных режимов обработки с применением инертных газов в качестве рабочей среды;

- резка горячим ножом - применяется исключительно в сырой керамике для разделения керамической заготовки на изделия, имеет высокую скорость обработки, особенно эффективна при групповом методе обработки деталей с высокой плотностью группы;

- прецизионная дисковая резка - применяется для получения прямого сплошного реза и скрайбирования как сырых, так и обожженных керамических изделий. Используется для разделения керамической заготовки на готовые платы или ее надрезки.

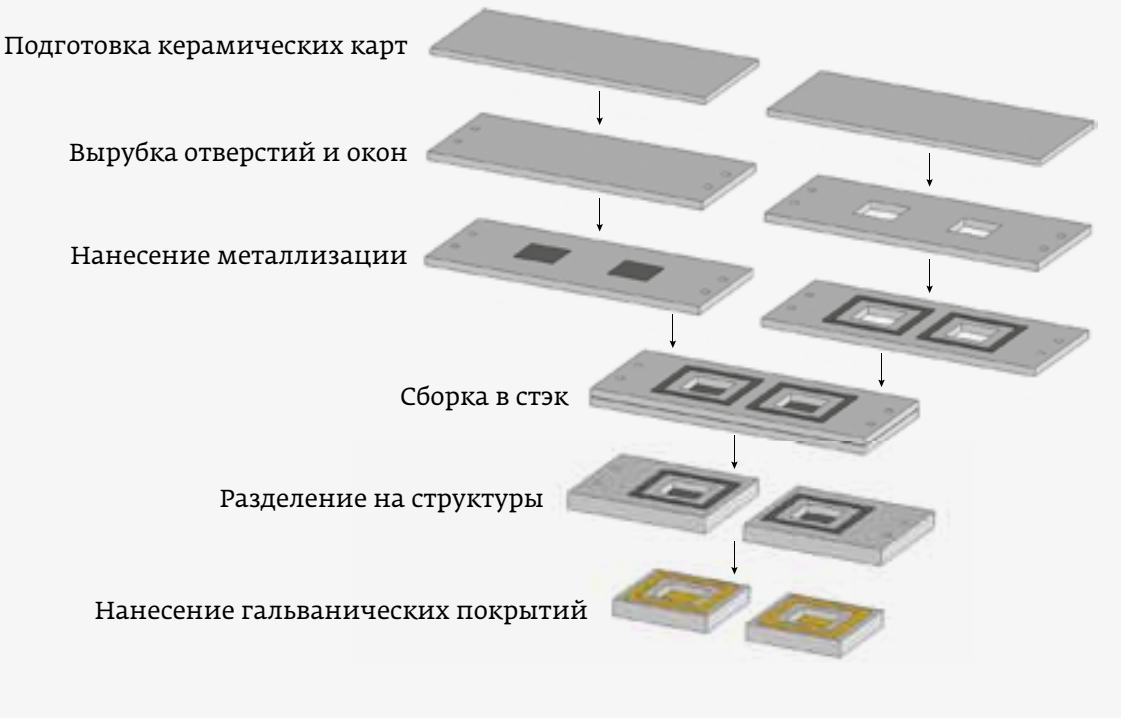

Рис. 2. Процесс производства многослойных металлокерамических плат 


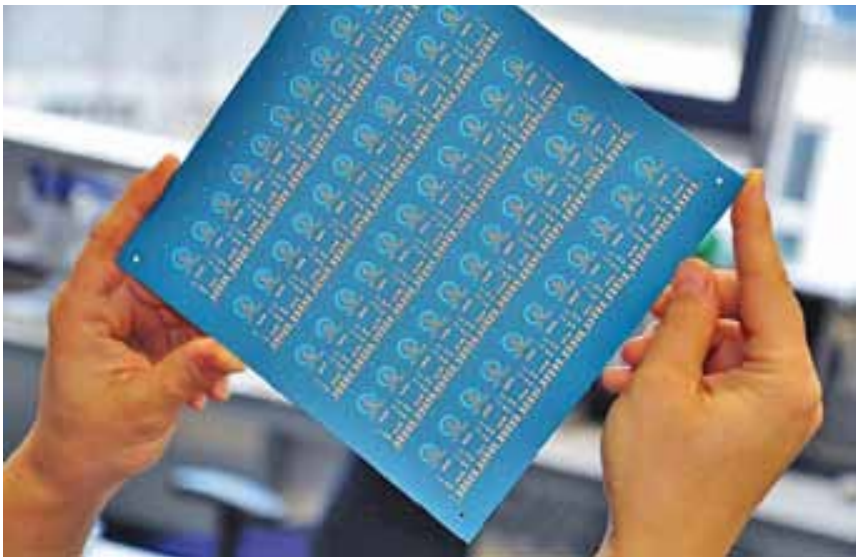

Рис. 3. Керамическая заготовка с расположенными на ней изделиями

Керамическая заготовка с расположенными на ней изделиями (групповой метод) показана на рис. 3.

С помощью специального оборудования производится скрайбирование и резка спеченной и сырой керамики, а также прошивка в ней отверстий. Вне зависимости от выбранного способа, точность обработки керамических изделий будет не хуже $\pm 0,02$ мм, что подтверждается встроенными в оборудование оптическими средствами автоматического контроля качества.

Керамические платы и подложки могут иметь как одно- или двухстороннюю сплошную металлизацию, так и топологический рисунок, сформированный в соответствии с техническими требованиями заказчика. Для металлизации керамических плат в АО «ТЕСТПРИБОР» наиболее часто применяют толстопленочную технологию Thick-Film (рис. 4a): проводящий топологический рисунок и изоляционные слои формируются путем нанесения металлизационной пасты с последующим вжиганием в защитной среде методом трафаретной печати. Толстопленочная технология нанесения металлизации позволяет формировать проводниковые слои толщиной в среднем от 25 до 50 мкм после процесса вжигания. В пастах для формирования толстопленочной металлизации методом трафаретной печати используются различные компоненты. Ввиду специфики термических процессов в основном применяются тугоплавкие металлымолибден и вольфрам, наиболее подходящие по физическим характеристикам для высокотемпературной керамики металлы. По требованию заказчика возможно нанесение металлизации драгоценными металлами, такими как серебро, серебропалладий, золото. Применение паст с драгоценными металлами особенно актуально для низкотемпературной керамики. Также возможно формирование элементов топологии из резистивной или диэлектрической пасты, что позволяет «печатать» на поверхности и внутри слоев керамических плат встроенные резисторы, конденсаторы и индуктивности.

Соответствие толщины и стабильность нанесения паст достигается при:

- строгом контроле физических параметров паст (вязкости, размера частиц и т.д.);

- грамотном выборе технологом используемого материала и режимов печати

Отдельную нишу в процессах нанесения металлизации на производстве AО «ТЕСТПРИБОР» занимают технологии DBC и STC (рис. 46). Эти технологии используются для изготовления керамических плат на основе $\mathrm{Al}_{2} \mathrm{O}_{3}$ (96\%) и AIN с металлизацией медью толщиной до 400 мкм, с возможностью последующего формирования заданного топологического рисунка фотолитографическими методами или методом вакуумного напыления и наращивания проводникового слоя через специальные маски.

Повышенные требования к качеству и точности нанесения металлизации выявили необходимость организации собственного изготовления сетчатых трафаретов. В условиях производства АО "ТЕСТПРИБОР" изготавливаются высококачественные сетчатые трафареты со следующими характеристиками:

- максимальный размер трафаретной рамы $450 \times 450$ мм;

- минимальный размер ячейки сетки - 0,038 мм;

- материал сетки - проволока из нержавеющей стали с минимальным диаметром 0,02 мм;

- точность изготовления фотошаблонов - не хуже 6 мКм.

Качество трафаретов, от которого напрямую зависит качество готовой металлизации, достигается за счет:

- использования высококачественной сетки, обеспечивающей высокую степень натяжения, малое удлинение, высокий предел текучести пасты;

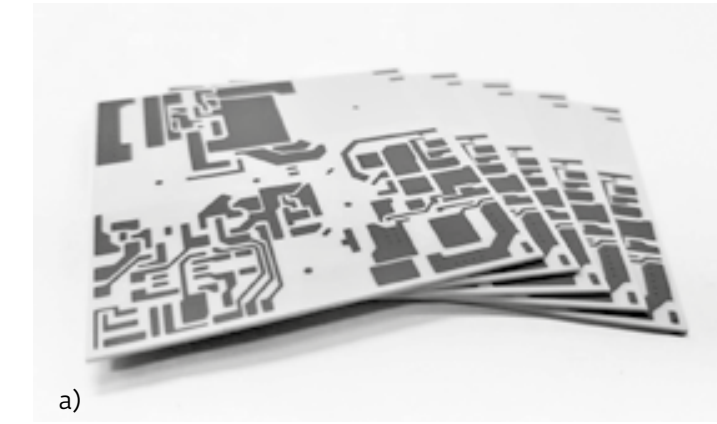

Рис. 4. Способы нанесения металлизации: а - толстопленочная технология; 6 - технологии DBC и STC 

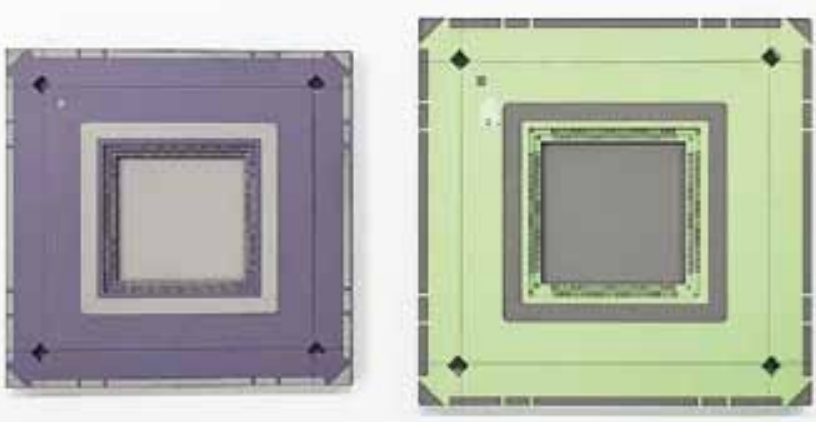

Рис. 5. Керамическая плата до обжига (слева) и после обжига (справа)

- точность геометрических параметров ячеек сетки позволяет строго контролировать расход пасты, а также получать точный допуск габаритов отпечатка;

- сетка натянута таким образом, что во время печати она максимально упруга, что повышает срок ее службы;

- высококачественный пленочный фоторезист обеспечивает постоянство и долговечность характеристик, отличное качество отпечатков и повторяеMOCTь.

Процесс вжигания производится в колпаковой печи в строго контролируемой по качеству газов в азотоводородной среде при температуре в диапазоне от 1300 до 1700 C. Получение качественной вакуумплотной керамики достигается благодаря использованию печей с программным управлением, точностью поддержания температуры до $\pm 0,1^{\circ} \mathrm{C}$ во всем диапазоне температур и газов особой чистоты. Строгий контроль за соблюдением технологических параметров гарантирует стабильность и управляемость процессов усадки керамики. Собственная газогенерирующая установка обеспечивает производство технологическими газами чистотой 99,9995\% (остаточная концентрация примесей не более 5 ppm). В зависимости от выбранного материала плат и подложек и сложности изделия процесс обжига может занимать до двух суток. Пример керамической платы до обжига и после обжига показан на рис. 5.

следующим этапом в изготовлении керамических плат и подложек является пайка - размещение на плате необходимых металлических элементов, например, ободков, необходимых для последующей герметизации монтируемых на плату электронных компонентов, экранов или теплоотводов. Применение графитовой оснастки собственного производства в паре с компьютерными методами расчета, а также применение специальных припойных материалов позволяют получить качественный спай между различными по коэффициенту теплового расширения материалами. На производстве АО «ТЕСТПРИБОР» применяется технология пайки керамики со следующими группами металлов: ковар, медь, псевдосплавы МД-40 и ВД-15, иные сплавы с медью/вольфрамом/молибденом, а также композитные многослойные материалы с повышенной теплопроводностью.

В рамках освоения различного рода экспериментальной и серийной продукции на производстве освоены следующие технологии нанесения гальванических покрытий:

- электрохимическое никелирование из растворов различных составов: толщина слоя покрытия до 30 мкм;

- электрохимическое никелирование сплавом никель-фосфор: толщина слоя покрытия до 30 мкм;

- химическое никелирование сплавами никельфосфор, никель-бор для изделий сложной формы и топологии с большим количеством изолированных монтажных площадок (в том числе на печатных платах): гарантированная толщина покрытия до 10 мкм. Электрохимическое золочение для проволочных выводов: толщина покрытия около 10 мкм;

- химическое и иммерсионное золочение: толщина покрытия, нанесенного химическим способом, от 0,5 до 2,5 мкм, толщина слоя иммерсионного покрытия до 0,15 мкм - для изделий сложной формы и топологии с большим количеством изолированных монтажных площадок (в том числе печатных плат), проволочных выводов.

Образцы гальванического покрытия приведены на рис. 6

В том случае, когда на детали имеется большое количество изолированных поверхностей (например, при производстве печатных плат), изделие имеет сложную форму, предпочтительно использовать химический способ
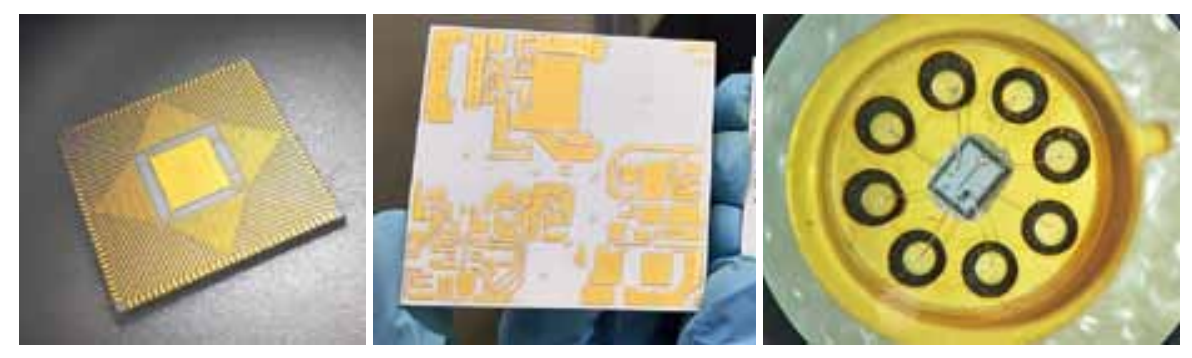

Рис. 6. Образцы гальванического покрытия 
нанесения. Такая технология в данном случае позволяет значительно повысить качество покрытия.

Для формирования подслоя под золотое покрытие, а также под металлизацию, выполненную из тугоплавких материалов (молибден, вольфрам) на керамических платах и подложках, используются покрытия сплавами никель-бор и никель-фосфор

При необходимости на никелевое покрытие можно нанести химическим или иммерсионным способами слой золота, толщина наносимого покрытия золотом может гарантированно достигать до 2,5-3 мкм. Проведенные испытания изделий с таким покрытием показали, что покрытие сохраняет паяемость и антикоррозионные свойства.

Благодаря всем перечисленным процессам на производстве АО «ТЕСТПРИБОР» освоены технологии полного цикла изготовления печатных плат на основе подложек из различных видов спеченной алюмооксидной и алюмонитридной керамики.

Высокое качество печатных плат гарантируется за счет следующих параметров:

- процесс изготовления керамических подложек для печатных плат полностью соответствует требованиям, предъявляемым к изделию;

- при производстве используются высококачественные трафареты для печати, изготавливаемые из определенных материалов с заданными характеристиками;

- строгий контроль физических параметров паст, грамотно подобранные составы, а также режимы нанесения и вжигания металлизации;
- особое внимание уделено проектированию оборудования и оснастки, позволяющим получать повторяемость по толщине, характеристикам металлизации и покрытия внутри партии, и достигать равномерности покрытия на одном изделии настолько, насколько позволяют его геометрические характеристики;

- качество используемых при покрытии гальванических растворов и постоянство технологических параметров четко контролируются производственной лабораторией и инженерным персоналом;

- уникальные, современные составы позволяют наносить как классические покрытия, так и редко используемые при обычной практике - например, золотое покрытие, полученное химическим способом до толщины более 2 мкм, что способствует решению широкого спектра задач;

- контроль качества изделий производится в несколько этапов по многим параметрам на 100\% продукции преимущественно неразрушающими (бесконтактными) методами, что снижает вероятность попадания бракованных изделий к заказчику.

$$
\text { s.t. }
$$

Таким образом, в АО «ТЕСТПРИБОР» освоен полный цикл производства керамических плат и подложек, в том числе изготовление уникальной технологической оснастки и трафаретов. Качество выпускаемой продукции строго контролируется на каждом этапе производства, что обеспечивает ее соответствие всем техническим требованиям заказчика.

\section{КНИГИ ИЗДАТЕЛЬСТВА "ТЕХНОСФЕРА»}

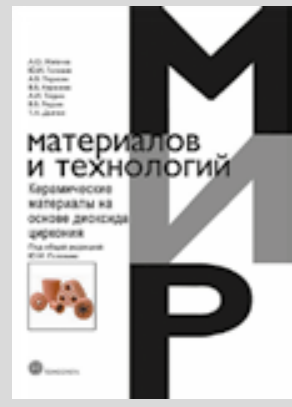

Цена 760 руб.

\section{КЕРАМИЧЕСКИЕ МАТЕРИАЛЫ} НА ОСНОВЕ ДИОКСИДА ЦИРКОНИЯ

Жигачев А. О., Головин Ю. И., Умрихин А. В., Коренков В. В., Тюрин А. И., Родаев В. В., Дьячек Т. А.

\section{Под общей редакцией Ю. И. Головина}

В книге обобщены данные по возможному химическому составу, кристаллической и микроструктуре, а также свойствам керамических материалов на основе диоксида циркония. Рассмотрены наиболее развитые технологии получения этих керамик и композитов на их основе. Монография состоит из четырех частей, каждая из которых освещает определенную область вопроСов, связанных с керамическими материалами.

Книга будет интересна широкому кругу читателей: от студентов естественно-научных специальностей до инженеров, технологов и медицинских работников, связанных с практическим применением циркониевой керамики.

Разработка методов синтеза, получение и подготовка оригинальных керамических образцов на основе бадделеита выполнены при поддержке гранта Российского научного фонда (проект № 16-19-10405). Отработка методик исследования и определение физико-механических характеристик осуществлены при поддержке гранта Министерства образования и науки Российской Федерации (проект № 16.2100.2017/ПЧ).

\section{КАК ЗАКАЗАТЬ НАШИ КНИГИ?}

$凶$ 125319, Москва, а/я 91; +7 495 234-0110; 8 +7 495 956-3346; knigi@technosphera.ru, sales@technosphera.ru 


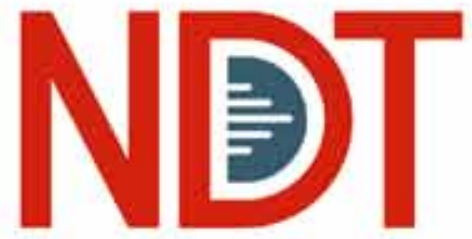

RUSSIA

NDT Russia

20-я Международная выставка оборудования

для неразрушающего контроля

27-29

октября

2020

Москва,

Крокус Экспо
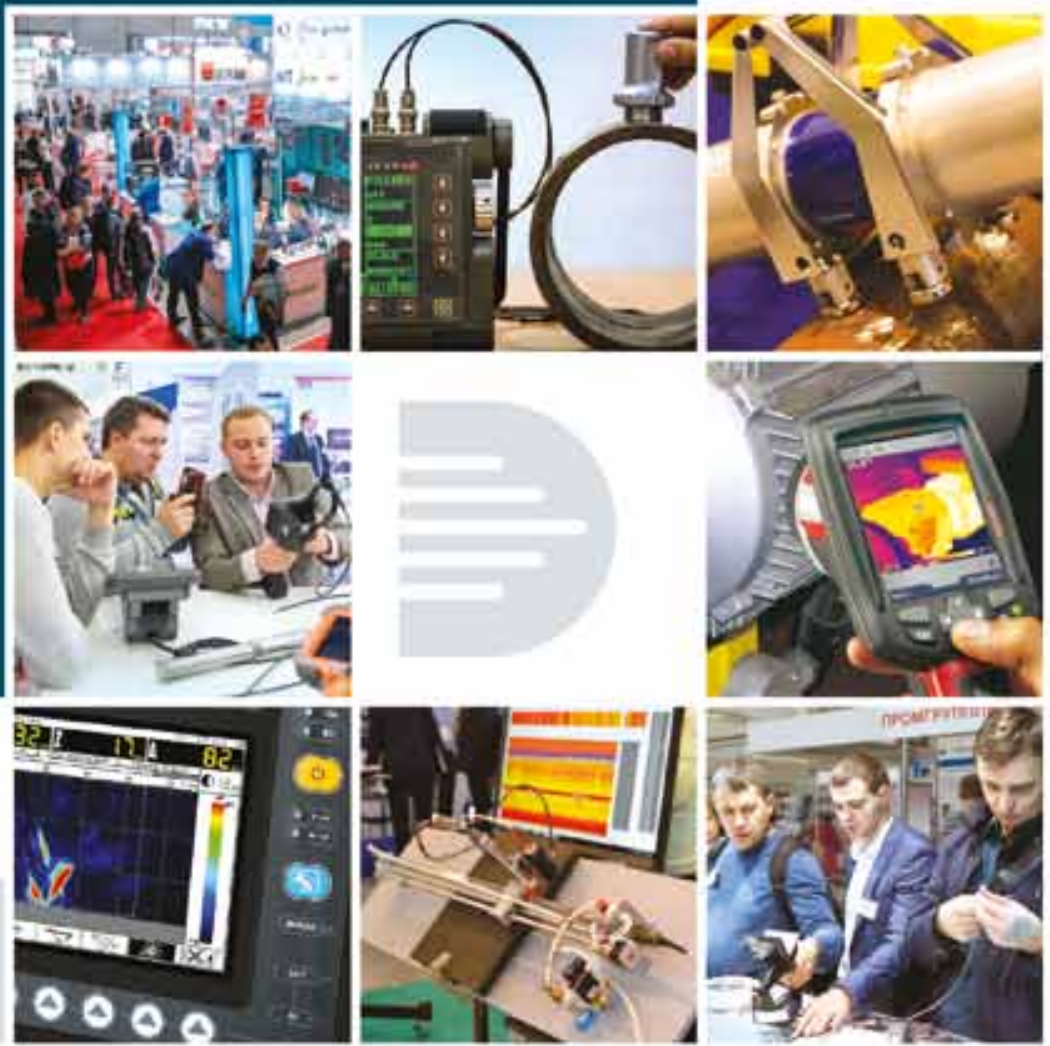

Oprativaarop - komnanens MVK Obuc is Cankt-Merep6ypre

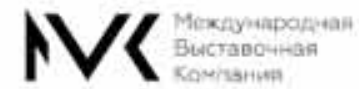

+7 (812) $3806010 / 00$ ndt@mvk.ru
Подробнее о выставке:

ndt-russia.ru 